\title{
LEADER una política para la dinamización del emprendimiento rural femenino en Murcia
}

\section{LEADER a policy to boost rural female entrepreneurship in Murcia}

\author{
Catalina Nicolás Martínez* (D) https://orcid.org/0000-0002-5641-8735 \\ Universidad de Murcia, España, catalina.nicolas@um.es \\ César García Pina (D) https://orcid.org/0000-0002-0638-3415 \\ Universidad de Murcia, España, cgarpina@gmail.com
}

Ángel Manzanares Gutiérrez (D) https://orcid.org/0000-0002-3382-1687

Universidad de Extremadura, España, amanzanares@unex.es

Prudencio José Riquelme Perea (D) https://orcid.org/0000-0001-93586554

Universidad de Murcia, España, halconps@um.es

\begin{abstract}
Rural women have evolved in recent decades, being considered a fundamental actor for the revitalization of the territory by rural development policies. In the literature (Stough, 2016; Bjärstig y Sandström, 2017; Navarro et al., 2018b), it is speculated that these policies, together with the alternative activity to agriculture, have encouraged women to become empowered by start a business and, with their activity, energize the rural environment. In order to contribute to the knowledge of the effectiveness of rural development policies, this research is proposed in which the cases of eleven female entrepreneurs benefiting from LEADER policies in Murcia (Spain) at least fifteen years ago are analyzed. The results indicate that female entrepreneurship caused both the dynamization of the territory and the professional development of rural women. In addition, it was observed that these policies attract women with distinctive characteristics and that the LEADER policy was decisive for them to decide to become entrepreneurs.
\end{abstract}

*Autora para correspondencia : Catalina Nicolás Martínez, catalina.nicolas@um.es

Recepción: 17/05/21

Aprobación: 24/09/21

Publicación: 28/10/21

Key words: LEADER initiatives, rural women, rural entrepreneurs, revitalization of the territory, Region of Murcia.

Resumen: La mujer rural ha evolucionado en las últimas décadas, siendo considerada actor fundamental para la dinamización del territorio por las políticas de desarrollo rural. En la literatura (Stough, 2016; Bjärstig y Sandström, 2017; Navarro et al., 2018b), se especula que estas políticas, junto con la actividad alternativa a la agricultura, han fomentado que las mujeres se empoderen al emprender y, con ello, dinamicen el medio rural. Para contribuir al conocimiento 
de la efectividad de las políticas de desarrollo rural se plantea esta investigación en la que se analizan los casos de 11 emprendedoras beneficiarias de políticas LEADER en Murcia (España) desde hace, al menos, quince años. Los resultados indican que el emprendimiento femenino provocó tanto la dinamización del territorio como el desarrollo profesional de las mujeres rurales. Además, se observó que estas políticas atraen a mujeres con características distintivas y que la política LEADER fue determinante para que decidieran convertirse en emprendedoras.

Palabras clave: política LEADER, mujer rural, emprendedoras rurales, dinamización del territorio, Región de Murcia.

\section{Introducción}

Los países difieren unos de otros principalmente por los recursos que poseen, así como por sus distintos estilos de vida. Pero estas diferencias no sólo ocurren de una nación a otra, en el mismo país se pueden encontrar grandes diferencias entre sus territorios (De Maya et al., 2020). Así, dentro del mismo país el medio rural y el urbano son considerados distintos desde hace décadas, debido tanto a los diversos estilos de vida como a los sistemas productivos existentes (van der Ploeg et al., 2015). Estas diferencias tienen su origen en las transformaciones económicas y sociales que se produjeron durante la Segunda Guerra Mundial, las cuales impactaron de forma distinta en el territorio, incluso dentro del medio rural (Rodríguez, 2000). Se dieron fenómenos de emigración, pérdida de actividad económica y servicios, bajo el contexto de la crisis de la agricultura tradicional (Esparcia, 2004).

Por ello, las áreas rurales se quedaron prácticamente marginadas, física y económicamente, con unas estructuras sociales también muy deterioradas, debido a la grave despoblación que estaba afectando a estas zonas (Esparcia, 2004; Nieto y Gurría, 2005). La despoblación de las zonas rurales se ha producido, sobre todo, por el éxodo de los jóvenes y adultos, unida a la baja natalidad y al envejecimiento poblacional. Además, la despoblación de los núcleos rurales también afecta al medioambiente y a la calidad de vida de sus habitantes. Pero no sólo esto, también debe tenerse en cuenta la pérdida de capital humano, en particular de los más emprendedores en la zona, lo cual disminuye el dinamismo económico (Pinilla y Sáez, 2017), ya que la literatura (Nicolás et al., 2019) indica que habitualmente son más emprendedores los jóvenes. 
Todo esto dio como resultado fuertes diferencias socioeconómicas entre las zonas rurales y las urbanas, pues mientras las rurales parecían perder su atractivo para la población, los territorios urbanos se convirtieron en zonas generadoras de empleo, actividad y riqueza (Nieto y Gurría, 2005; Nieto y Cárdenas, 2015 y 2017).

No obstante, en los años ochenta se produjo el proceso de reconversión industrial. Este proceso provocó en las zonas urbanas grandes bolsas de desempleo, pérdida del atractivo, así como la transición de una economía de los servicios a una economía de la información. Dicha transición generó un empleo cada vez más cualificado, al que no tuvieron acceso los excedentes agrarios no cualificados (Nieto y Gurría, 2005).

Pero el proceso de globalización, las dificultades de la agricultura europea y el agotamiento de la Política Agraria Común (PAC) promovieron nuevas actividades económicas en los territorios rurales. El medio rural dejó de basar su economía en la producción agrícola y ganadera, tomando importancia actividades relacionadas con el ocio, lo lúdico, lo recreativo, el movimiento poblacional, las mayores relaciones interpersonales... De ahí que Europa elabore nuevas políticas de desarrollo rural no basadas exclusivamente en la agricultura (Navarro et al., 2008; Lukic y Obad, 2016). Por ello se considera que si se quiere desarrollar el medio rural es necesario optimizar sus comunicaciones. La mejora de la accesibilidad de estos territorios (ferrocarril y carretera) permitiría minimizar la situación de periferia e integrar las poblaciones rurales en el conjunto del territorio. Además, esto también produciría la integración de las oportunidades de mercado, tanto en el sector agrario como en el industrial (Cánoves et al., 2006).

Desde entonces, el medio rural ha evolucionado de forma más dinámica, desapareciendo las barreras para intercambiar ideas, mensajes, productos y servicios, así como para el desplazamiento de las personas (Rizzo, 2013). Principalmente, han sido las mejoras en las infraestructuras y comunicaciones las que han hecho posible que el mundo rural avance ante el aislamiento que sufría (García, 2011; Cárdenas y Nieto, 2016). Por ello, actualmente el medio rural está asociado al término desarrollo, pero siguen existiendo acontecimientos incontrolables relacionados con desequilibrios demográficos, socioeconómicos y territoriales, como la despoblación, masculinización, niveles de edad avanzada, mayores niveles de pobreza, menores salarios, oferta de menor número de puestos de trabajo cualificados, debilidad institucional, insuficientes infraestructuras, deficientes comunicaciones... (Hervás y Castelló, 2014; Dax y Fisher, 2018). 
El cambio del medio rural ha afectado en mayor medida el estilo de vida de la mujer, por eso, tanto la Ley 45/2007, para el Desarrollo Sostenible del Medio Rural (BOE, 2007), la PAC, como la iniciativa comunitaria de desarrollo rural LEADER (siglas francesas de Liaisons entre Activités de Developement de L'Économie Rural, que significan Enlaces entre Acciones para el Desarrollo de la Economía Rural) insisten en la importancia de este colectivo para conseguir sus objetivos (Bjärstig y Sandström, 2017). Indican que es necesario empoderar a las mujeres, incentivando su formación y liderazgo, estableciendo medidas de conciliación familiar y laboral para fomentar que emprendan (Navarro et al., 2008; Stough, 2016; Navarro et al., 2018b).

Con base en lo expuesto, se planteó esta investigación para contribuir al conocimiento de la efectividad de las políticas de desarrollo rural; es decir, comprobar si estas medidas han promovido la dinamización del territorio rural a través del emprendimiento femenino. Para cumplir este objetivo, en el presente trabajo, en primer lugar, se analiza la literatura sobre políticas LEADER y la mujer rural. En segundo lugar, siguiendo la metodología del estudio de casos, se indaga sobre el papel de la política LEADER y el fomento del emprendimiento femenino, analizando las características personales y profesionales de 11 emprendedoras beneficiarias desde hace más de quince años de ayudas LEADER, así como las características de las empresas que pusieron en marcha.

Las emprendedoras pertenecían a zonas rurales de la Región de Murcia, comunidad autónoma que se encuentra en el sureste de España. Este territorio, con una gran tradición en el sector agrícola, es considerado en los ambientes agrícolas como la "Huerta de Europa". Finalmente, en el apartado de las conclusiones, se destaca el empoderamiento observado en la mujer rural, ya que gracias a la ayuda LEADER, decide emprender y, con esa actividad económica, dinamizar el medio rural. Pero no sólo eso, también se han podido identificar características distintivas personales y familiares de estas mujeres rurales, así como las de su proceso emprendedor.

\section{Iniciativa de Desarrollo Rural LEADER y mujer rural}

Desde los años cincuenta, el medio rural europeo sufre un deterioro económico y social producido por las transformaciones económicas y reestructuraciones del sector agrícola (Cárdenas y Nieto, 2020). En esos años se pasa de una agricultura de subsistencia a una competitiva, siendo necesaria la inversión y modernización empresarial que no todos los agricultores pudieron asumir. Mientras tanto, en las zonas urbanas se desarrolló la economía 
industrial y años más tarde la economía de servicios, gracias a las políticas públicas de concentración de inversiones. Estas circunstancias son las causantes de las diferencias socioeconómicas entre las zonas rurales y las urbanas, ya que para la concentración de las inversiones productivas, la parte urbana se convierte en núcleos generadores de empleo, actividades y riqueza (Méndez y Caravaca, 1996; Nieto et al., 2019).

Años después, a finales de los setenta y principios de los ochenta, la crisis económica de los precios del petróleo cambia la situación del medio rural y urbano. El medio urbano cae en una regresión económica, no pudiéndose insertar en él a los trabajadores procedentes del medio rural. Por eso, el esfuerzo de la administración se centra en mantener a la población en las zonas rurales, partiendo de que se deben igualar las características socioeconómicas de las zonas urbanas con las rurales y así disminuir los flujos migratorios hacia las ciudades (Nieto y Cárdenas, 2017).

Este argumento, recogido en documentos de la Unión Europea, como "El futuro del mundo rural" (Comisión de las Comunidades Europeas, 1988) y la Estrategia Territorial Europea (Comité de Desarrollo Territorial, 1999), da comienzo al diseño de nuevas ayudas para el desarrollo rural basadas en tres aspectos: 1) igualar el nivel de vida entre el medio urbano y el rural; 2) favorecer la implantación de actividades productivas diversificadas, potenciando los sectores industrial y de servicios; y 3) frenar la despoblación y la decadencia de las zonas rurales (Cánoves et al., 2006; Lukic y Obad, 2016).

Para mejorar el nivel de vida en el medio rural se potencia la diversificación de actividades, teniendo como fuente de los principales actores e iniciativas al medio local (Esparcia et al., 2016; Moyano et al., 2017). Desde esta perspectiva, el foco de atención cae sobre el sector turístico, considerándose que es y será un factor imprescindible para desarrollar las zonas rurales, al generar nuevas posibilidades de ingresos para su población con los recursos naturales que posee el territorio (Loscertales, 1999; Navarro et al., 2018a).

También se considera necesario actuar en el sector agrario, ya que su evolución a lo largo de los últimos años ha puesto de manifiesto su incapacidad para el desarrollo de las áreas rurales (Majoral y Sánchez, 2001). Así, desde Europa se plantean modelos para recuperar actividades abandonadas, desarrollar otras con las que utilizar las nuevas tecnologías y los cambios en la demanda, estimular a los actores para llevarlas a cabo, así como movilizar a dichos actores en el contexto local con las herramientas adecuadas (Esparcia et al., 2016; Moyano et al., 2017).

Justamente, para movilizar el medio rural, la Unión Europea ha puesto en marcha cantidad de actuaciones, como las Reformas de los Fondos 
Estructurales realizadas en la década de 1980, los diferentes cambios de la PAC (en la que se incrementaban las aportaciones para diversificar actividades y el decrecimiento del número de ayudas directas a la producción), la creación del concepto de desarrollo rural en la Declaración de Cork (Conferencia Europea, 1996) o el fomento de la gestión pública local desarrollando la metodología "de abajo a arriba" o "bottom-up" con la creación de la iniciativa LEADER I en 1991 (Nieto y Cárdenas, 2017; Nieto et al., 2019; Miles y Morrison, 2020).

En concreto, el 15 de marzo de 1991 surge la Iniciativa Comunitaria LEADER I en el seno de la Comisión de Agricultura, Pesca y Desarrollo Rural, respecto a lo acordado en el artículo 11 del Reglamento (CEE) núm. 4253/88 (Diario Oficial de las Comunidades Europeas, 1988). Nace como una alternativa para las zonas comunitarias rurales afectadas por la reconversión de la PAC, con el fin de apoyar el desarrollo de las comarcas rurales situadas en las regiones menos desarrolladas de la Unión Europea (regiones de objetivo 1) o las zonas rurales de otras regiones (objetivo 5b). Las regiones beneficiarias de estas iniciativas LEADER se modificaron con el paso de los años, extendiéndose a todo el territorio, como se indica en el Cuadro 1 . $^{1}$

El objetivo de la iniciativa LEADER fue demostrar que era posible impulsar el desarrollo de las zonas rurales mediante un enfoque integrado, concebido a nivel local con la participación de la población afectada a través de sus instituciones y sus organizaciones representativas (los Grupos de Acción Local). O lo que es lo mismo: la metodología LEADER, dentro de las políticas de la Unión Europea, destaca por su planteamiento original, ya que estimula la organización de grupos locales para que diseñen los proyectos de desarrollo que consideran más adecuados y no la puesta en marcha en el territorio de una serie de programas generales diseñados por la propia Comisión Europea. Es decir, se trata de una política de desarrollo descentralizada, donde se cede la iniciativa y el protagonismo a quienes van a ser los beneficiarios (Ruiz et al., 2000).

De este modo, se entiende que esta iniciativa intenta paliar desequilibrios estructurales, el envejecimiento de la población, la desaparición o deterioro de los servicios públicos y privados, y la escasa renovación de actividades tradicionales (MAPA, 2004; Blanco y Benayas, 1994; Moyano et al., 2017). Siete fueron las diferentes medidas (productivas y no productivas) que a través de las subvenciones globales se financiaban parcialmente por los Programas de Desarrollo. Estas medidas se exponen en el Cuadro 2.

1 Todos los cuadros y las figuras se encuentran en el Anexo, al final del presente artículo (Nota del editor). 
Como se puede observar, fue la medida 3, relacionada con la financiación de instalaciones y acondicionamientos de casas particulares, establecimientos e instalaciones turísticas y de ocio que favorezcan la creación de una oferta de turismo respetuoso con el medioambiente, a la que mayor importancia se le otorgó con 51,8\% de financiación.

Asimismo, se debe poner de manifiesto que la iniciativa LEADER se rige por el principio de cofinanciación en sus ayudas, de manera que a las subvenciones procedentes de la Unión Europea se deben añadir las aportaciones de los fondos públicos nacionales y de los agentes privados. El Cuadro 3 muestra la distribución de las cargas presupuestarias. Cabe indicar que la distribución porcentual del presupuesto recogida en el Cuadro 3 es un promedio, pues hay muy diversas variedades en los distintos proyectos, en los cuales no se mantiene necesariamente la misma proporcionalidad entre agentes privados y públicos.

Por ello, el método LEADER se presentó como un modelo totalmente diferente para el desarrollo rural, apareciendo conceptos como endógeno, integrado, innovador, demostrativo y participativo (MAPA, 1998; Esparcia et al., 2016). Esta nueva forma de pensar ha provocado, en muchos de los territorios beneficiados, el comienzo de una dinámica positiva de desarrollo global e integral que ha supuesto un aumento de la actividad económica y una disminución de la despoblación (Cárdenas y Nieto, 2020).

También cambió la forma de actuar de la población, la cual se convirtió en el auténtico motor de gestión en el desarrollo de las actividades, objetivo de esta iniciativa comunitaria. Por ello, diversas zonas beneficiadas por las políticas LEADER muestran un dinamismo que va aumentando año tras año desde 1990, lo que contrasta con lo sucedido hasta entonces, donde la marginación iba en incremento desde mediados del siglo XX. Por este motivo se considera que la aplicación de las políticas orientadas a paliar los desequilibrios territoriales es la causante del cambio ocurrido (Hernández et al., 2008; Moyano et al., 2017).

Precisamente, el método LEADER atiende a la doble dimensión del desarrollo rural (Esparcia, 2012; Nieto y Cárdenas, 2018). La primera es la que comprende la diversificación productiva, compuesta por sectores tradicionales y por más innovadores. Por este motivo, cuando se analiza el término desarrollo rural, se atiende principalmente al sector del turismo rural, aunque no se olvida cualquier tipo de sector en general, teniendo en cuenta aquellos estratégicos que mantengan relación con el medio ambiente y la formación. La segunda dimensión del desarrollo rural es la dinamización de la sociedad local. Este eje preocupa en mayor medida a los gestores de la iniciativa 
LEADER, pretendiendo que se involucre en la toma de decisiones estratégicas y se desarrolle el capital humano que realiza la función de actor y benefactor (Esparcia et al., 2016; Nieto y Cárdenas, 2017).

La Ley 45/2007, para el Desarrollo Sostenible del Medio Rural (BOE, 2007), y la PAC van más allá, identificando a la mujer como el principal actor para el desarrollo del medio rural. De hecho, la PAC define a la mujer rural como un agente fundamental para desarrollar efectos positivos en el medio rural, no sólo atendiendo a la actividad productiva. En la misma línea, Aguilar et al. (2009), Navarro et al. (2014) o Navarro et al. (2018b) muestran que estas mujeres son un colectivo preferente en las Políticas de Desarrollo Rural tanto nacionales como europeas. Es más, existen investigaciones que concluyen, para el caso de los Pirineos, que el método LEADER es mayoritariamente femenino (Hervás y Castelló, 2014), lo cual pone de manifiesto la implicación y el avance de la mujer en el medio rural en materia de crecimiento y desarrollo de su entorno (Stough, 2016).

Asimismo, hay autores que argumentan que son las funciones que la mujer rural desarrolla las que hacen que sea tan necesaria y beneficiosa para el territorio (Navarro et al., 2008; Navarro et al., 2014; Navarro et al., 2018b). Estas funciones se exponen en la Figura 1. Al analizarlas, se observa que son fuente de empleo para la mujer rural, ya sea por cuenta ajena o propia; las salidas profesionales por dichas funciones se recogen en la Figura 2. En resumen, las funciones que la mujer rural realiza a diario -a pesar de ser efecto del rol femenino secundario y subsidiario en el terreno laboral (López et al., 2019) - son fuente de oportunidades para que se conviertan en emprendedoras (Navarro et al., 2014; Nicolás et al., 2019).

No obstante, en la literatura se debate si las políticas de autoempleo, como las LEADER, pueden ser perjudiciales para las mujeres rurales. Ehlers y Main (1998) o Navarro et al. (2018b) afirman que afianzan el papel secundario de la mujer en el mercado laboral y, además, deben asumir la responsabilidad ante un posible fracaso empresarial. Pero Grasmuck y Espinal (2000), Nicolás y Rubio (2016) y Nicolás et al. (2019) entienden que la emprendedora contribuye al mantenimiento familiar, consiguiendo una mayor autonomía y capacidad para tomar decisiones en los ámbitos profesional y social.

Ese empoderamiento de la mujer puede provocar conflictos, debido al afianzamiento de la ideología patriarcal que aún hoy existe en la mayoría de los territorios rurales. Grasmuck y Espinal (2000) especifican que la mujer debe subordinar sus obligaciones como empresaria a las obligaciones familiares; y si la empresa es exitosa, el hombre puede ver amenazado su estatus 
en el hogar, de ahí que se puedan producir tensiones y disputas en el ámbito privado.

Esto provoca la reflexión sobre la eficiencia de las políticas de desarrollo rural; es decir, si éstas además de dinamizar y desarrollar el medio rural, también empoderan a la emprendedora beneficiaria de una política, la LEADER.

\section{Metodología}

El objetivo de esta investigación es avanzar en el conocimiento sobre la efectividad de las políticas de desarrollo rural y comprobar si estas medidas dinamizan el medio rural a través del emprendimiento y el empoderamiento femenino. Para alcanzar este objetivo, siguiendo a Darke et al. (1998), se plantea un estudio de casos, metodología apropiada cuando una investigación trata de explicar fenómenos cuyo desarrollo teórico se encuentra en las primeras fases de formalización, como es el caso que nos ocupa. El método adecuado para este estudio es la entrevista en profundidad, ya que se puede obtener información personalizada y subjetiva relevante para la investigación.

\section{Muestra}

No existe un acuerdo sobre el número ideal de casos a la hora de trabajar con esta metodología. Algunas investigaciones (Yin, 1989; Eisenhardt, 1989; Martínez, 2006) indican que con un rango de entre cuatro y diez se trabaja bien; con menos de cuatro es difícil generar una teoría compleja y es, quizás, empíricamente inconveniente; con más de diez casos, la investigación puede volverse compleja por el volumen de datos. El presente trabajo cuenta con una muestra de 11 mujeres. Con este número fue con el que se empezó a saturar la información recopilada.

La población se ha obtenido de la base de datos de la iniciativa comunitaria LEADER en Murcia. El motivo de elegir a esta comunidad autónoma se debe a los resultados destacados por Martínez et al. (2007), cifrando la media española de expedientes en $34,68 \%$ e inversiones en 33,33\%, casi diez puntos porcentuales por debajo de la media de Murcia, cuyas cifras se situaban en $43,4 \%$ y $40,3 \%$, respectivamente.

La zona de actuación de la iniciativa LEADER en la Región de Murcia estuvo formada por las comarcas del Noroeste, Río Mula (excepto Sierra Espuña) y Pedanías Altas de Lorca. En concreto, esta zona ascendía a un total de 3.693 kilómetros cuadrados y a más de 85.000 habitantes. Solamente en la primera iniciativa LEADER, en Murcia se invirtieron casi siete millones 
de euros, aportados tanto por la Comunidad Europea, las Administraciones Central, Autonómica y Locales, y la iniciativa privada. Esta cifra llegó a ascender a 29.303 millones de euros en la tercera edición del programa LEADER en Murcia (García, 2011). Cabe destacar que todas las emprendedoras que forman la muestra solicitaron las ayudas LEADER en las tres primeras ediciones.

Como se ve en la Figura 3, la Región de Murcia se sitúa en el sureste de España, ocupa una superficie de $11.317 \mathrm{~km}^{2}$ y está formada tanto por zonas de montaña (al encontrarse en el extremo oriental de las Cordilleras Béticas) como costeras (al estar ubicada en pleno centro del Arco Mediterráneo peninsular). En ella se encuentra el Mar Menor, la laguna salada permanente más grande de Europa (con $180 \mathrm{~km}^{2}$ de superficie). La delimitación de sus zonas rurales y urbanas también se muestra en la Figura 3.

La distribución de la población entre sus municipios se expone en la Figura 4. La mayor concentración de población se observa en las tres ciudades de la región: Murcia, Cartagena y Lorca. Cabe destacar que la capital (Murcia) es la séptima ciudad más poblada de España. Pero no sólo eso, como era de esperar, se observa, en la Figura 4, que las zonas rurales tienen menor densidad de población que las urbanas.

Para seleccionar los casos que forman la muestra de este estudio se tuvieron en cuenta tres criterios:

1) Ser mujer.

2) Haber puesto en marcha una iniciativa empresarial en el medio rural.

3) Ser beneficiaria de una política LEADER en la Región de Murcia.

Las características de las 11 emprendedoras rurales que forman la muestra se exponen en el Cuadro 4.

\section{Recogida de información}

La información se reunió mediante entrevistas personales con 11 emprendedoras rurales. El método de recogida de información se realizó mediante la entrevista directa que permite la interacción con las entrevistadas, solucionando así las dudas que puedan surgir. Las entrevistas se llevaron a cabo entre el 3 de mayo y el 23 octubre de 2018, y su duración osciló entre 40 y 100 minutos.

Las entrevistas se prepararon con anterioridad, manejando como guion un cuestionario que, para considerarlo definitivo, fue probado con un caso piloto. El cuestionario consta de 69 preguntas estructuradas en ocho bloques: datos generales, datos formativos, experiencia profesional, datos de 
los miembros del hogar, reparto de tareas del hogar, datos de su empresa, datos sobre la creación de su empresa y otros datos.

\section{Resultados}

Los resultados se han estructurado teniendo en cuenta si la información analizada versa sobre las características personales y profesionales de las mujeres rurales o sobre el proceso emprendedor que iniciaron hace más de quince años, como se ve a continuación.

\section{Caracterización de emprendedora rural}

Los resultados de las entrevistas permitieron caracterizar a las mujeres rurales que fundaron su empresa, ayudadas por la iniciativa LEADER. Los resultados indicaron que emprenden con una edad media e incluso elevada en algunos casos; en concreto, sus edades oscilan entre 30 y 51 años. Esta situación coincide con la observada en la literatura (Navarro et al., 2018a), en la cual se afirma que emprende tanto población joven, que se inicia en la actividad, como población adulta que lo hace para crear su propia empresa o para buscar un complemento a los ingresos familiares.

El 100\% de las emprendedoras eran mujeres de nacionalidad española y la mayoría estaban casadas, con las salvedades de la emprendedora 3 (separada) y la emprendedora 9 (soltera). A excepción de las emprendedoras 9 y 5 , tenían hijos que estaban estudiando cuando fundaron su empresa, concretamente dos hijos, salvo la emprendedora 8 que tenía tres.

El Cuadro 5 muestra que la mayoría de las entrevistadas contaban con un nivel formativo superior; precisamente ocho de las 11 emprendedoras habían cursado estudios universitarios. Estos resultados son coincidentes con los de Navarro et al. (2014), quienes afirman que las mujeres rurales suelen marcharse a la ciudad para formarse. La excepción a esta situación se encuentra en las emprendedoras 5, 8 y 11. Dos de estas últimas explicaron su nivel de estudios de la siguiente manera: "Mi madre decía que a las mujeres no nos hacía falta, porque luego nos casábamos" (emprendedora 5); y la emprendedora 11 indicó: "Me hubiera gustado estudiar más, pero por motivos personales no pude seguir con mis estudios". Además, las tres destacaban que después sí habían realizado diversos cursos para tener una formación adecuada con la cual dirigir su empresa. 
Pero no sólo las menos formadas, la totalidad de las entrevistadas actualizaban su formación casi todos los años, como se desprende de las siguientes afirmaciones:

Sí, la verdad es que hago cursos casi todos los años. Antes de Gestión y Administración y todo eso que era en lo que ayudaba a mi marido en el negocio que llevábamos. Y ahora todo lo que hago está relacionado con el turismo (emprendedora 5).

La formación en temas rurales es constante. Ahora mismo estoy perfeccionando el inglés, porque se me había olvidado bastante. Estoy haciendo un cursillo de esos (emprendedora 6).

Aunque realizaban cursos habitualmente, la mayoría no sabía en qué debía formarse en un futuro, como puso de manifiesto la emprendedora 3: "No tengo ahora mismo algo en mente", y la 6:

Como siempre estás metida en la red y todo eso, y además como autónomos y todo eso nos mandan mucha información. Siempre hay cursos para hacer. Y el LEADER nos manda y siempre hay alguno que hacemos. Siempre estamos liadas. Pero vamos, que la formación es continua respecto al mundo rural.

En lo que sí coincidió la mayoría de las emprendedoras $(1,2,8,9,10$ y 11) es que les gustaría seguir formándose en un futuro. Se considera que las afirmaciones de estas seis emprendedoras estaban relacionadas con su edad, al ser ellas las entrevistadas más jóvenes. La menor edad lleva aparejado una menor experiencia, lo cual implica que consideren que necesitaban más formación para suplir esa menor experiencia o, simplemente, que al ser las más jóvenes fueran menos reacias a seguir formándose.

Como ocurrió con la actualización formativa, también hubo unanimidad en la experiencia profesional de las emprendedoras. Todas habían trabajado con anterioridad a la creación de su empresa, pero sólo las emprendedoras 2 y 7 tenían experiencia profesional en el sector en el que habían fundado su empresa.

Cuando se les preguntó si habían formado una empresa previa a la actual, sólo las emprendedoras 1, 7, 10 y 11 indicaron que no. Las siete restantes habían tenido otras empresas antes, de las que tres siguen en activo (emprendedoras 2, 4 y 9 ).

Para ahondar en las características personales, se les preguntó sobre la gestión de sus hogares, información esencial para conocer si la mujer rural sigue desempeñando el rol que la sociedad patriarcal le atribuye (Navarro et al., 2014; Nicolás et al., 2018). Así, comenzando con el número de miembros del hogar, se observó que las cifras oscilaban entre tres y cinco, siendo predominante los hogares formados por cuatro miembros, como ocurría con las 
emprendedoras 1, 2, 4, 6,7 y 11. La excepción en este punto se encontró en la emprendedora 9, ya que vivía sola.

Respecto a la situación de los maridos, la mayoría se encontraba trabajando, salvo el de la emprendedora 5, que se había jubilado, y el de la emprendedora 11, que estaba desempleado tras cerrar su empresa de más de treinta años de antigüedad, debido a la fuerte crisis económica iniciada a finales de 2007. Cabe destacar que se encontraron maridos (emprendedoras 2 y 8 ) que trabajaban en la empresa fundada por la mujer rural objeto de este estudio.

Atendiendo a la situación de los hijos, se comprobó que, en la mayoría de los casos, permanecían en el domicilio, pues estaban estudiando cuando las mujeres emprendieron (emprendedoras 1, 2, 3, 4, 6, 7, 8, 10 y 11). La excepción fue la emprendedora 5 , cuyos hijos se habían independizado; no obstante, su hogar estaba integrado por tres miembros al estar la emprendedora cuidando de su padre.

Una vez identificados los componentes del hogar, se analizó cómo se repartían las tareas domésticas. Comenzando por las horas de dedicación, llamó la atención que cuando se les preguntó cuántas horas destinaban semanalmente a dichas tareas, la mayoría respondió que bastante más de ocho (máximo reflejado en el cuestionario). Sin embargo, las emprendedoras 3 y 4 afirmaron que dedican una media de cuatro a seis horas; mientras que la emprendedora 7 indicó que de cero a dos horas. Esta disminución de tiempo se justifica porque esas emprendedoras tenían contratada a una empleada del hogar.

Las tres emprendedoras anteriores afirmaron que destinaban menos de ocho horas a las tareas domésticas, pero en realidad son cinco las entrevistadas que contaban con una empleada del hogar para realizar tareas de limpieza (emprendedoras 2, 3, 4, 7 y 11). No obstante, las horas que la tenían contratada difería. En el caso de la emprendedora 2, la empleada estaba contratada por tres horas; en el de la emprendedora 11, cuatro horas; en los casos de las emprendedoras 4 y 7 , ocho horas; mientras que en el de la emprendedora 3 eran 15 horas. Sin embargo, la emprendedora 5, pese a que indicó que no tenía contratada una empleada del hogar, afirmó: "Últimamente viene una chica a atender a mi padre, pero en mi casa no hace nada". Por lo tanto, aunque no contaba con una empleada para tareas que la emprendedora consideraba como propias del hogar, sí que realizaba la de cuidado de un mayor.

El Cuadro 6 muestra el reparto de tareas entre los miembros de la familia ( sin contar a la entrevistada). A simple vista, se puede pensar que, en la mayoría de los casos, existía un reparto equitativo. No obstante, se comprobó que 
si bien colaboraban otros miembros del hogar, el peso de las tareas continuaba recayendo en ellas. Se observó que en el hogar de la emprendedora 7 se producía un mayor reparto, seguido de la emprendedora 1; mientras que sus opuestos se encontraron en los hogares de las emprendedoras 5 y 11.

Cabe puntualizar que el hogar de la emprendedora 5 tenía unas características especiales al contar el cónyuge con una incapacidad severa. Sin embargo, el caso de la emprendedora 11 fue realmente llamativo: aunque el marido y el hijo estaban desempleados y la hija era estudiante, ninguno realizaba alguna tarea. Es más, todas recaían en la emprendedora, aun siendo la única que trabajaba fuera del hogar. De ahí que se entendiera la afirmación de la emprendedora: "Si colaboraran más en mi casa podría dedicarle más tiempo", refiriéndose a su empresa. Sus palabras corroboran que se siguen subordinando las obligaciones empresariales a las familiares en el caso de las mujeres rurales (Grasmuck y Espinal, 2000).

El Cuadro 6 también indica que los cónyuges solían realizar las mismas tareas, caracterizadas por ejecutarse fuera del hogar. Se comprueba que los maridos, en la mayoría de los casos, no hacen las principales tareas o las que, al menos, mayor tiempo ocupan y su realización es diaria, como son la preparación de comidas o el mantenimiento de la casa.

Por tanto, en casi todos los casos, el peso de las tareas seguía recayendo en la mujer, teniendo que compatibilizarlo con el trabajo que efectuaba en la empresa. Este hecho se constata, pues a pesar de que las emprendedoras manifestaron que otros miembros del hogar colaboraban en las tareas domésticas (con la excepción de la emprendedora 11), cuando en un primer momento se les preguntó sin enumerarles la lista de tareas, sólo las emprendedoras 1, 6 y 7 contestaron afirmativamente. En este punto, resultó explicativa la respuesta de la emprendedora 8 , quien, aunque se le formuló una pregunta cerrada, afirmó: "colaboran poco". Todo indica la existencia de problemas de conciliación laboral y familiar para estas mujeres. Este argumento es con el cual se explica que las empresas de las mujeres rurales tienen mayor probabilidad de cerrar frente a las creadas por hombres (Navarro et al., 2018b).

Una vez identificadas las características personales y profesionales de las emprendedoras rurales, es necesario conocer las de su proceso emprendedor, que se exponen a continuación.

\section{Caracterización del proceso emprendedor}

Comenzando con las características de las empresas, fueron creadas entre 1993 y 2005, y continúan en activo. Las políticas LEADER habían ayudado 
a las mujeres rurales a poner en marcha empresas exitosas con las cuales movilizar recursos y generar riqueza para la zona.

Los sectores de actividad escogidos fueron diversos, aunque predominaron las empresas del sector servicios, mayoritariamente de turismo rural; hecho que coincidió con lo que se argumentaba en la literatura (García, 2011; Nieto y Cárdenas, 2017).

Todas las mujeres, a excepción de la emprendedora 11, habían iniciado una actividad en la que ningún familiar había trabajado o creado una empresa antes. En cambio, la actividad de la emprendedora 11 fue desarrollada años atrás por sus padres y abuelos. Estos resultados no son de extrañar, pues era la única que se dedicaba al sector agrario. Es más, explicó que trabajaba en los mismos campos de vid que sus antepasados, pero que la empresa no fue heredada, sino que gracias a la ayuda LEADER adquirió las instalaciones que habían sido de sus antepasados y volvió a poner en marcha esos terrenos. También comentó que había adquirido más terrenos con el paso de los años.

La mayor parte de las entrevistadas era propietaria de los locales donde desarrollaba su actividad, excepto la emprendedora 1, quien aunque realizó una gran reforma en el local para comenzar su actividad, hoy en día lo sigue manteniendo alquilado. Solamente las emprendedoras 2 y 7 adquirieron el local para llevar a cabo su labor empresarial. En concreto, la emprendedora 7 lo hizo para trasladar su sede social y fue más adelante cuando decidió rehabilitar la vivienda y crear una empresa de turismo rural. Las restantes emprendedoras tenían en propiedad unas viviendas; al conocer la posibilidad que les brindaba la política LEADER (financiación, acompañamiento y formación), decidieron rehabilitarlas y explotar un nicho de mercado como fue el turismo rural.

Esto explica por qué ocho de las 11 emprendedoras no vivían en la zona donde tenían la empresa. Precisamente, la vivienda de la zona rural es la que fue rehabilitada o reformada para crear la empresa turística. No obstante, es destacable que sólo las emprendedoras 1, 2 y 9 desarrollaran su actividad en el mismo municipio donde vivían; esto indica que las restantes se habían marchado a vivir a la ciudad o a municipios cercanos. La política LEADER provocó que estas mujeres aprovecharan los recursos que tenían a su alcance y fundaran una empresa en la zona rural donde habían nacido. De ahí que los resultados sean consecuentes con lo que se argumenta en la literatura (Navarro et al., 2014; Navarro et al., 2018a) respecto a que las mujeres se van de las zonas rurales para alcanzar un alto nivel educativo y tener un mejor futuro profesional en la ciudad; pero también que con la metodología 
LEADER se consigue que mujeres rurales vuelvan al medio rural para emprender (Navarro et al., 2014).

Sobre los trabajadores, el número oscilaba entre uno y tres. Todas afirmaron que necesitaban ayuda en su actividad empresarial, pero no coincidían en el tipo de relación contractual para contratar dicha ayuda. Por ejemplo, las empresas de turismo rural preferían una relación mercantil, frente a la relación laboral que escogían las emprendedoras restantes. Las emprendedoras turísticas argumentaron que no siempre contaban con el mismo número de clientes y que no podían contratar a empleados permanentemente, por lo que subcontrataban a empresas externas. Una situación especial fue la de la emprendedora 11, la cual indicó que en su empresa agrícola, cuando era la temporada de recolección contrataba a trabajadores, y que el resto del año realizaba sola el trabajo de riego, poda y labranza, aunque recibía colaboración esporádica exclusivamente de su padre, a pesar de que el marido y el hijo estuvieran desempleados.

Como se ha comentado, todas las emprendedoras continuaban con su actividad empresarial. Pero no sólo eso, la mayoría ya había efectuado ampliaciones a su empresa y, además, tenía pensado seguir ampliándola, ya sea de tamaño o de servicios ofertados. No obstante, indicaron que por la situación económica debían ser prudentes.

Si se atiende a los motivos por los cuales iniciaron su actividad, se comprobó que hubo argumentos diferentes, casi todos relacionados con características personales de las emprendedoras, como muestra el Cuadro 7.

Respecto al desembolso inicial, sería un error pensar que utilizaron pequeñas cantidades, aunque la literatura (Navarro et al., 2014; Navarro et al., 2018a) indica que las inversiones de las emprendedoras son menores a las realizadas por los emprendedores. Las inversiones dependieron de la actividad de la empresa y de si el local era propiedad de las emprendedoras. De hecho, solamente las emprendedoras 7 y 10 afirmaron que su desembolso no fue elevado. La emprendedora 7 comenzó con una empresa de educadora ambiental que fue ampliando, por ello su inversión inicial fue de tres mil euros; mientras tanto, la emprendedora 10 contaba con una casa en perfectas condiciones y no tuvo que hacer ninguna reforma.

No obstante, estas emprendedoras manifestaron que efectuaron numerosas ampliaciones, en las cuales invirtieron gran cantidad de dinero. Para el resto de las emprendedoras -y ya incluyendo las ampliaciones anteriormente nombradas-, su inversión osciló entre 30.000 y 600.000 euros. Cabe destacar que la totalidad de las entrevistadas señaló que esa fue su estimación, pero que finalmente el desembolso fue mayor. 
Respecto a las fuentes de financiación, las emprendedoras utilizaron recursos propios, además de la ayuda LEADER. Las emprendedoras 2 y 7 también optaron por otros tipos de ayudas como las ICO (Instituto de Crédito Oficial, que se encuentra adscrito al Ministerio de Economía, Industria y Competitividad), y además la 7 se benefició de la subvención de Mujeres Empresarias, concedida por el Instituto de la Mujer. Llama la atención que aunque las inversiones fueron de cantidades considerables, sólo las emprendedoras 1 y 2 optaron por financiación bancaria. La literatura (Navarro et al., 2018a) destaca el mayor compromiso de la emprendedora con la actividad creada cuando invierte, principalmente, recursos propios; situación observada en este trabajo y que, de ser así, también explica que las empresas continúen operando en la actualidad pese a las dificultades de conciliación familiar.

Sobre la situación laboral antes de constituir su empresa, de las 11 entrevistadas cinco estaban desempleadas, mientras que las seis restantes ya contaban con una empresa y decidieron crear la actual, como ocurrió con las emprendedoras 2, 4 y 9, para ampliar los servicios que ya tenían. En este punto se debe destacar de las emprendedoras 6 y 8 que debido a la constitución de su nueva empresa, cerraron la anterior, a pesar de que una de ellas emprendiera por recomendación para aprovechar la ayuda LEADER.

Sin embargo, resultó sorprendente que tres de las emprendedoras indicaran que no consideran su iniciativa empresarial como una salida laboral. Este hecho puede ser explicado en la literatura (Navarro et al., 2018a), en la cual se afirma que este tipo de empresas pueden ser creadas como complemento para el mantenimiento familiar. Al analizar esos tres casos, se observó que dos de ellos iniciaron esta actividad teniendo una empresa ya en activo; tal vez por ello, consideraban la constitución de la nueva empresa como un complemento, como se afirma en la literatura (Sampedro y Camarero, 2007; Navarro et al., 2008; Martínez et al., 2007; Hervás y Castelló, 2014; Navarro et al., 2018b), y no como una salida en sí. No obstante, una de esas emprendedoras (la 6) cesó su anterior empresa y actualmente sólo se dedica a la iniciativa empresarial que aquí se está analizando. Por su parte, la emprendedora 9 explicó al respecto: "Más que un trabajo lo considero un hobby".

Por último, las mujeres señalaron las ventajas e inconvenientes de ser empresarias y, como se ve en el Cuadro 8, las respuestas fueron similares a las recogidas en la literatura (Sampedro y Camarero, 2007). La mayoría destacó como ventaja la flexibilidad horaria, pero también que esa flexibilidad era compatible con jornadas laborales más largas que si trabajaran por cuenta ajena, desventaja que también apuntaban. Además, destacaron el 
inconveniente de la gran responsabilidad que recaía sobre ellas por gestionar su propia empresa, hecho que se argumentaba en la literatura (Sampedro y Camarero, 2007). Estos resultados se entienden debido al rol de género que desempeñan las mujeres rurales, así como al menor apoyo familiar que tienen cuando deciden emprender (Navarro et al., 2014); situación que ha sido corroborada por las entrevistadas a lo largo de su discurso.

Finalmente, se formuló una pregunta abierta por si las emprendedoras querían agregar algo que no se les había preguntado durante la entrevista. La mayoría indicó que había tenido ciertos problemas a la hora de iniciar la actividad empresarial y en la subsistencia de la misma; en el Cuadro 9 se exponen algunas de estas problemáticas.

En general, se distinguieron diferentes problemas con determinados organismos públicos. Resultó llamativo que las emprendedoras de turismo rural afirmaran que necesitaban mayor implicación por parte de los ayuntamientos locales para impulsar el turismo de la zona. Por otro lado, el hecho de que emprendedoras de distintos municipios se sintieran discriminadas por razón de género ante determinados organismos públicos fue una revelación realmente alarmante. Y más aún si se atiende a la literatura (Navarro et al., 2018a), donde se afirma que para el desarrollo de la metodología LEADER, los colectivos más implicados son los ayuntamientos y las mujeres, frente a jóvenes, desempleados y agricultores.

\section{Conclusiones}

Este estudio surgió con el objetivo de avanzar en el conocimiento sobre la efectividad de las políticas de desarrollo rural, concretamente las de la metodología LEADER, y su papel en el empoderamiento de la mujer rural y fomento del emprendimiento femenino en estos territorios. Para poder alcanzarlo, primero se revisó la literatura sobre políticas de desarrollo rural, centrando la atención en las LEADER y su relación con la mujer rural. Al examinar la literatura se comprobó que este tema es novedoso y suscita gran interés, ya que la situación del medio rural ha cambiado con los años, y lo cierto es que se considera al colectivo femenino actor clave en el desarrollo del territorio (Bjärstig y Sandström, 2017). Por ello, era necesario poner en marcha políticas que empoderaran a este colectivo para que decidiera crear una empresa, dar trabajo, atraer población y, con ello, desarrollar el medio rural (Navarro et al., 2008; Stough, 2016; Navarro et al., 2018b).

Para conseguir el objetivo fijado, tras analizar la literatura, se realizó la parte empírica, utilizando la metodología cualitativa de estudio de casos que, 
como afirman los expertos, es la necesaria cuando se investiga un fenómeno cuyo desarrollo teórico se encuentra formalizándose (Yin, 1989; Eisenhardt, 1989; Martínez, 2006). La muestra estuvo formada por 11 beneficiarias de políticas LEADER que emprendieron en la Región de Murcia (comunidad autónoma con un elevado porcentaje de participación e inversión en este tipo de ayudas) (Martínez et al., 2007) y que hoy en día se pueden considerar emprendedoras exitosas, al tener sus empresas más de 15 años de antigüedad.

Los resultados de este trabajo ponen de manifiesto que, como apuntaba la literatura (Blanco y Benayas, 1994; Loscertales, 1999; Cánoves et al., 2006; García, 2011; Navarro et al., 2014; Nieto y Cárdenas, 2017) e indicaba la propia política LEADER, la mayoría de las mujeres entrevistadas (ocho) emprendió en el sector del turismo rural y, además, dos de las restantes en sectores relacionados con el servicio a personas. Solamente una emprendedora se dedicaba al sector primario (Navarro et al., 2018b). Por tanto, las funciones destacadas en la literatura (Navarro et al., 2008; Navarro et al., 2018b) que se les atribuían a las mujeres rurales sí ejercen un efecto positivo a la hora en que ellas decidieran emprender.

Las mujeres rurales emprendieron en un periodo de auge económico. Los motivos fueron diferentes, aunque coincidían en ciertas características personales; cabe recordar que cinco de ellas estaban desempleadas y que consideraban la constitución de la empresa como una salida laboral. Con base en Sampedro y Camarero (2007), en esta investigación las mujeres destacaron como ventajas de ser empresarias la flexibilidad de horarios y la satisfacción personal o autorrealización. Además, se identificaron dos inconvenientes. A pesar de la flexibilidad, la carga horaria es mayor que si trabajaran por cuenta ajena y la responsabilidad es muy elevada. Los argumentos de las emprendedoras rurales tienen relación con que ellas siguen desempeñando el rol de género que la sociedad patriarcal les atribuye, haciéndoles difícil conciliar la vida laboral y familiar, de ahí que creen una empresa con la cual consiguen mayor flexibilidad horaria (Nicolás y Rubio, 2016).

Resultó llamativo que ocho de las 11 mujeres residieran en la capital o en municipios cercanos. La mayoría se había marchado de la zona rural y fue precisamente la política LEADER la que suscitó que utilizaran su antigua vivienda para crear una empresa de turismo rural (Navarro et al., 2014). Además, es destacable que un factor relevante para emprender fuera la ayuda LEADER y que invirtieran principalmente recursos propios. Esto demuestra un mayor compromiso de las emprendedoras con su empresa, lo que también ayudaría a la consolidación de la misma (Navarro et al., 2018a). 
Sobre sus características personales, las mujeres rurales emprendían ya contando con experiencia previa como trabajadoras por cuenta ajena y, por lo tanto, no son tan jóvenes como argumenta la literatura sobre emprendimiento (Nicolás et al., 2019). Además, tenían una formación elevada debido a que se habían marchado del medio rural a la ciudad (Navarro et al., 2014). Es más, mantienen esa formación actualizada gracias, entre otras cosas, a la preparación que les ofrecen desde LEADER. Pero no sólo ello, aparte de su trabajo retribuido, también eran trabajadoras dentro del hogar, manteniendo las funciones que se les atribuyen por cuestión de género (Nicolás y Rubio, 2016; Navarro et al., 2018b). Por tanto, eran madres de familia y responsables de la mayoría de las tareas domésticas (Marín et al., 2019). Aunque el resto de los miembros "colaboraba", las tareas del hogar seguían sin repartirse equitativamente. Por este motivo, las emprendedoras rurales contrataban a una empleada que les ayudaba a conciliar su vida laboral y familiar.

En conclusión, los resultados muestran que la política LEADER ha sido determinante para que las mujeres rurales emprendieran y se desarrollaran profesionalmente en un trabajo que les apasiona. Asimismo, se comprueba cómo las emprendedoras desarrollan el territorio; además de su propia actividad y el trabajo directo que crean, subcontratan a otras empresas para determinadas funciones y atraen a personas a la zona con sus empresas turísticas. Como indicaba la literatura (Blanco y Benayas, 1994; Loscertales, 1999; Cánoves et al., 2006; García, 2011; Navarro et al., 2014; Nieto y Cárdenas, 2017), el sector turístico es el principal beneficiario de estas políticas y apenas lo es el agrario. También se observó un perfil concreto entre las mujeres beneficiarias de estas ayudas, quienes tenían una elevada formación, eran mayores de 30 años, contaban con experiencia laboral y crearon su empresa con recursos económicos propios; empresa que la mayoría consideraba una salida profesional, la cual habían consolidado con el paso de los años, invirtiendo en ella tanto económica como formativamente.

Por lo tanto, se puede calificar a la práctica de la política rural LEADER en la Región de Murcia como exitosa. Se ha observado que se han puesto en valor recursos endógenos, se han movilizado recursos exógenos, se ha atraído población, se ha dinamizado la zona, se han generado puestos de trabajo y se ha empoderado a la mujer rural al emprender. De ahí que se coincida con Navarro et al. (2018a: 216) cuando afirman: "Pocos programas públicos han tenido unos resultados y efectos tan positivos para el desarrollo rural, y con efectos e impactos que han perdurado tan largo tiempo, pese a los años transcurridos". 


\section{Referencias}

Aguilar, Encarnación et al. (2009), "Entre la tradición y la innovación: Políticas de empleo femenino y desarrollo rural”, en Sociología del Trabajo, núm. 65, España: Universidad Complutense de Madrid.

Bjärstig, Therese y Sandström, Camila (2017), "Public-private partnerships in a Swedish rural context - A policy tool for the authories to achieve sustainable rural development?", en Journal of Rural Studies, núm. 49, Reino Unido: Pergamon y Elsevier Science.

Blanco, Ricardo y Benayas, Javier (1994), "El turismo como motor de desarrollo rural. Análisis de los proyectos de turismo subvencionados por LEADER I", en Revista de Estudios Agrosociales, núm. 49, España: Ministerio de Agricultura, Pesca y Alimentación (MAPA).

BOE (2007), "Ley 45/2007, para el Desarrollo Sostenible del Medio Rural, de 13 de diciembre”, en Boletín Oficial del Estado, núm. 299, España: Jefatura del Estado.

Cánoves, Gemma et al. (2006), "Políticas públicas, turismo rural y sostenibilidad: difícil equilibrio", en Boletín de la Asociación de Geógrafos Españoles, núm. 41, España: Asociación Española de Geografía.

Cárdenas, Gema y Nieto, Ana (2020), "El Enfoque LEADER en el nuevo FEADER 20142020 en Extremadura”, en Cuadernos Geográficos, núm. 59, España: Universidad de Granada.

Cárdenas, Gema y Nieto, Ana (2016), "Desarrollo rural en Extremadura. Perspectivas de Futuro (2014-2020)”, en Ruiz Pulpón, Ángel et al. [eds.], Treinta años de Política Comunitaria Agraria Común en España: Agricultura y multifuncionalidad en el contexto de la nueva ruralidad, España: Óptima.

Centro Regional de Estadística de Murcia (2019), Portal Estadístico de la Región de Murcia. Disponible en: https://econet.carm.es/ [20 de octubre de 2020].

Comisión de las Comunidades Europeas (1988), "El futuro del mundo rural", en Boletín de las Comunidades Europeas, suplemento 4/88, Bélgica: Oficina de Publicaciones Oficiales de las Comunidades Europeas.

Comité de Desarrollo Territorial (1999), Estrategia Territorial Europea, Alemania: Comisión Europea.

Conferencia Europea (1996), Declaración de Cork, Irlanda: Comisión Europea.

Darke, Peta et al. (1998), "Successfully completing case study research: combining rigour, relevance and pragmatism”, en Information Systems Journal, núm. 8, Reino Unido: Wiley-Blackwell Publishing.

Dax, Thomas y Fischer, Michael (2018), "An alternative policy approach to rural development in regions facing population decline”, en European Planning Studies, núm. 26, Reino Unido: Routledge Journals y Taylor \& Francis.

De Maya, Manuel et al. (2020), "Measurement of Quality of Life in Spanish Regions”, en Applied Research in Quality of Life, Holanda: Springer Netherlands.

Diario Oficial de las Comunidades Europeas (1988), "Reglamento (CEE) núm. 4253/88", en Diario Oficial de las Comunidades Europeas, $n^{\circ}$ L 374 del 31.12.1988, Luxemburgo: Publications Office of the European Union.

Eisenhardt, Kathleen (1989), "Building theories from case Study Research", en Academy of Management Review, núm. 14, Estados Unidos: Academy of Management. 
Ehlers, Tracy y Main, Karen (1998), "Women and the False Promise of Microenterprise”, en Gender and Society, núm. 12, Estados Unidos: Sage.

Esparcia, Javier et al. (2016), "Una aproximación al enfoque del capital social y a su contribución al estudio de los procesos de desarrollo local”, en Journal of Regional Research Investigaciones Regionales, núm. 34, España: Universidad de Alcalá.

Esparcia, Javier (2012), "Evolución reciente, situación actual y perspectivas futuras en el desarrollo rural en España y en la UE”, en Revue Marocaine d'Administration Locale et de Développment, núm. 79, Marruecos: Fondation Hanns-Seidel d’Allemagne.

Esparcia, Javier (2004), "Las políticas de desarrollo rural: evaluación de resultados y debate en torno a sus orientaciones futuras”, en García Pascual, Francisco [ed.], El mundo rural en la era de la globalización: incertidumbres y potencialidades, España: Ministerio de Agricultura, Pesca y Alimentación (MAPA).

García, Ramón (2011), “Turismo y desarrollo rural en la comarca del noroeste de la región de Murcia: los programas europeos LEADER”, en Cuadernos de Turismo, núm. 27, España: Universidad de Murcia.

Grasmuck, Sherri y Espinal, Rosario (2000), "Market success or female autonomy? Income, ideology and empowerment among microentrepreneurs in the Dominican Republic", en Gender and Society, núm. 14, Estados Unidos: Sage.

Hernández, María et al. (2008), "Las actividades turísticas-residenciales en las montañas valencias”, en Ería. Revista cuatrimestral de Geografía, núm. 75, España: Universidad de Oviedo.

Hervás, María Inmaculada y Castelló, Ana (2014), “Mujeres emprendedoras con la metodología LEADER en las zonas de montaña del Pirineo Aragonés”, en Hervás, María Inmaculada [ed.], Entre noche y día no hay pared. Mujeres en el medio rural, España: Red Aragonesa de Desarrollo Rural.

López, María et al. (2019), "Análisis de la segregación ocupacional por género en España y la Unión Europea (2002-2017)”, en Prisma Social: Revista de Investigación Social, núm. 26, España: Fundación iS+D para la Investigación Social Avanzada.

Loscertales, Blanca (1999), "El turismo rural como forma de desarrollo sostenible. El caso de Aragón”, en Geographicalia, núm. 37, España: Universidad de Zaragoza.

Lukic, Aleksandar y Obad, Orlanda (2016), "New actors in rural development - the LEADER Approach and Projectification in Rural Croatia”, en Sociologija i proctor, núm. 54, Croacia: Inst Social Res Zagreb.

Luzón, José Luis y Pi, Cristina (2002), "La iniciativa comunitaria Leader de desarrollo rural en Europa: la experiencia de Catalunya”, en Revista Econômica do Nordoste, núm. 30, Brasil: Banco Do Nordoste.

Majoral, Roser y Sáncheza, Dionisio (2001), "Assimetrias territoriais e áreas marginais em Espanha”, en Caetano, Lucília [ed.], Territorio, inovaçao e trajectorias de desenvolvimiento, Portugal: Centro de Estudios Geográficos da Fluc.

MAPA (Ministerio de Agricultura, Pesca y Alimentación) (2004), "Mucho en común. El estado de la cooperación en LEADER+", en Actualidad LEADER. Revista de Desarrollo Rural, núm. 26, España: Ministerio de Agricultura, Pesca y Alimentación (MAPA).

MAPA (Ministerio de Agricultura, Pesca y Alimentación) (1998), "El LEADER I en España. Una experiencia innovadora”, en Actualidad LEADER. Revista de Desarrollo Rural, núm. 1, España: Ministerio de Agricultura, Pesca y Alimentación (MAPA). 
Marín, Longinos et al. (2019), "How Gender, Age and Education Influence the Entrepreneur's Social Orientation: The moderating Effect of Economic Development", en Sustainability, núm. 11, Suiza: MDPI.

Martínez, Emilia et al. (2007), Mujeres emprendedoras en el desarrollo rural. Atlas Regional de España de la participación de las mujeres rurales emprendedoras en la Iniciativa Comunitaria LEADER II, España: Ministerio de Asuntos Sociales.

Martínez, Piedad Cristina (2006), "El método de estudio de caso. Estrategia metodológica de la investigación científica”, en Pensamiento y Gestión. Revista de la División de Ciencias Administrativas de la Universidad del Norte, núm. 20, Colombia: Universidad del Norte.

Méndez, Ricardo y Caravaca, Inmaculada (1996), Organización industrial y territorio, España: Síntesis.

Miles, Morgan P. y Morrison, Mark (2020), "An effectual leadership perspective for developing rural entrepreneurial ecosystems”, en Small Business Economy, núm. 54, Países Bajos: Springer.

Ministerio para la Transición Ecológica y el Reto Demográfico (2019), "MFE (Mapa Forestal de España) de Máxima Actualidad. Región de Murcia”. Disponible en: https://www. miteco.gob.es/es/cartografia-y-sig/ide/descargas/biodiversidad/mfe_Murcia.aspx [20 de octubre de 2020].

Moyano, Pedro Benito et al. (2017), "La participación de los agentes económicos y sociales en la revitalización de los municipios rurales", en Journal of Regional Research Investigaciones Regionales, núm. 38, España: Universidad de Alcalá.

Navarro, Francisco Antonio et al. (2018a), "Análisis a largo plazo de las actuaciones en desarrollo rural neoendógeno. Continuidad de las empresas creadas con la ayuda de LEADER y PRODER en tres comarcas andaluzas en la década de 1990", en Revista de Estudios sobre Despoblación y Desarrollo Rural, núm. 25, España: Universidad de Granada.

Navarro, Francisco Antonio et al. (2018b), "Emprendedores y proyectos fallidos de LEADER y PRODER en Andalucía en el periodo 2000-2006. Perfil y motivos de desistimiento", en Estudios Geográficos, núm. 284, España: Consejo Superior de Investigaciones Científicas.

Navarro, Francisco et al. (2014), "Reflexiones en torno a la participación en el desarrollo rural. ¿Reparto social o reforzamiento del poder? LEADER y PRODER en el sur de España”, en Revista Latinoamericana de Estudios Urbano Regionales, núm. 121, Chile: Pontificia Universidad Católica de Chile.

Navarro, María Jesús et al. (2008), Situación de la mujer en el medio rural de la Región de Murcia, España: Consejería de la Política Social, Mujer e Inmigración de la Comunidad Autónoma de la Región de Murcia.

Nicolás, Catalina et al. (2019), "Social Entrepreneur: Same or Different from the Rest?, en Voluntas: International Journal of Voluntary and Nonprofit Organizations, núm. 30, Estados Unidos: Springer New York.

Nicolás, Catalina et al. (2018), "Cognitive Determinants of Social Entrepreneurship: Variations According to the Degree of Economic Development", en Journal of Social Entrepreneurship, núm. 9, Reino Unido: Taylor and Francis. 
Nicolás, Catalina y Rubio, Alicia (2016), "Social enterprise: Gender gap and economic development", en European Journal of Management and Business Economics, núm. 25, Reino Unido: Emerald Group Publishing.

Nieto, Ana y Cárdenas, Gema (2018), “The rural development policy in Extremadura (SW Spain): Spatial Location Analysis of Leader Projects”, en International Journal of GeoInformation, núm. 76, Suiza: MDPI.

Nieto, Ana y Cárdenas, Gema (2017), "25 años de políticas europeas en Extremadura: turismo rural y Método LEADER”, en Cuadernos de Turismo, núm. 39, España: Universidad de Murcia.

Nieto, Ana y Cárdenas, Gema (2015), "El método LEADER como política de desarrollo rural en Extremadura en los últimos 20 años (1991-2013)”, en Boletín de la Asociación de Geógrafos Españoles, núm. 69, España: Asociación Española de Geografía.

Nieto, Ana y Gurría, José Luis (2005), “Análisis de la población de los programas de desarrollo rural en Extremadura mediante sistemas de información geográfica", en Cuadernos Geográficos, núm. 36, España: Universidad de Granada.

Nieto, Ana et al. (2019), "Principal component Analysis of the LEADER Approach (20072013 ) in South Western Europe (Extremadura and Alentejo)”, en Sustainability, núm. 11, Suiza: MDPI AG.

Pinilla, Vicente y Sáez, Luis Antonio (2017), La despoblación rural en España: Génesis de un problema y politicas innovadoras, España: Centro de Estudios sobre Despoblación y Desarrollo de Áreas Rurales.

Rizzo, Fulvio (2013), "Leader policy practices and landscapes in the light of the agencystructure debate: evidence from LEADER local action groups in Italy and in Finland", en European Countryside, núm. 3, República Checa: Mendel University in Brno.

Rodríguez, Francisco (2000), "Desarrollo rural y desigualdades en España”, en Miranda Bonilla, José et al. [ed.], Hacia un nuevo espacio euromediterráneo, España: Asociación Española de Geografía (AGE).

Ruiz, Enrique et al. (2000), "La iniciativa comunitaria Leader II y el desarrollo rural: el caso de Aragón”, en Geographicalia, núm. 38, España: Universidad de Zaragoza.

Sampedro, Rosario y Camarero, Luis (2007), "Mujeres empresarias en la España rural. El sujeto pendiente de desarrollo”, en Revista Internacional de Sociología, núm. 65, España: Consejo Superior de Investigaciones Científicas.

Stough, Roger (2016), "Entrepreneurship and Regional Economic Development: some reflections”, en Journal of Regional Research Investigaciones Regionales, núm. 36, España: Universidad de Alcalá.

Van der Ploeg, Jan Douwe et al. (2015), "Rural development: actors and practices”, en Research in Rural Sociology and Development, núm. 22, Reino Unido: Emerald Group Publishing Limited.

Yin, Robert (1989), Case Study Research. Design and Methods (Applied Social Research Methods), Reino Unido: Sage. 

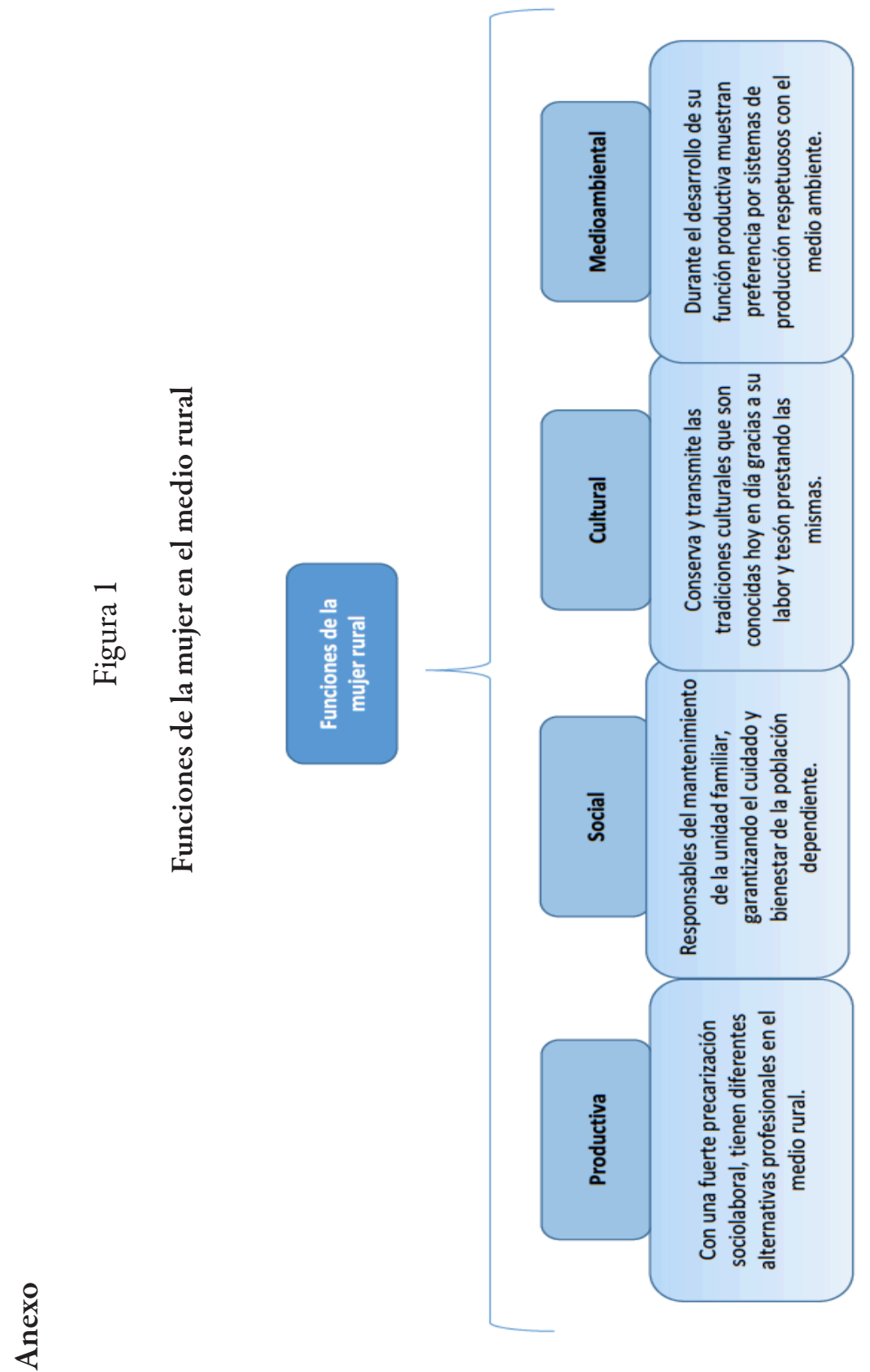

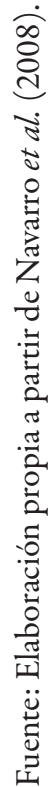




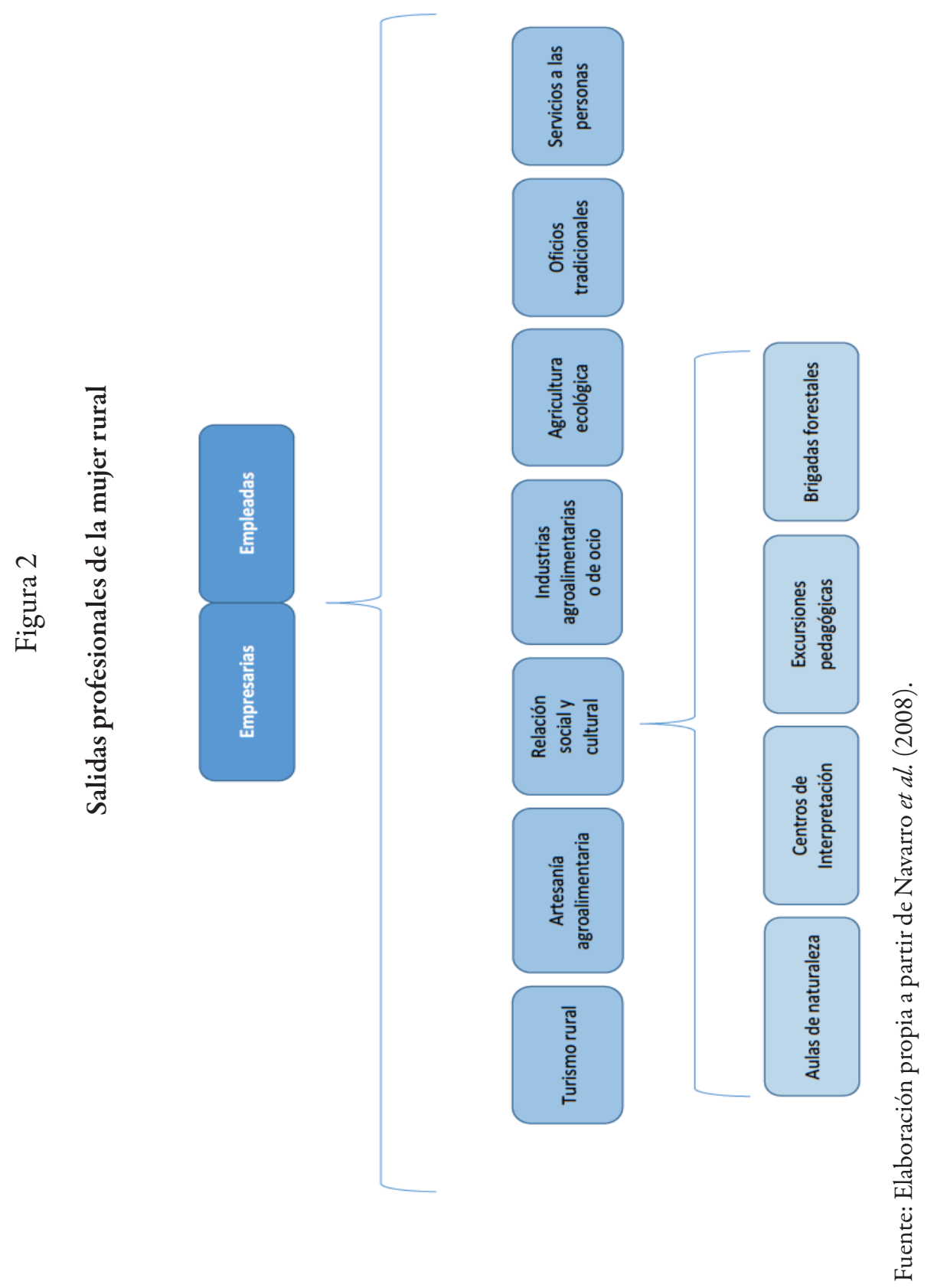




\section{Figura 3}

\section{Delimitación urbana y rural de la Región de Murcia}

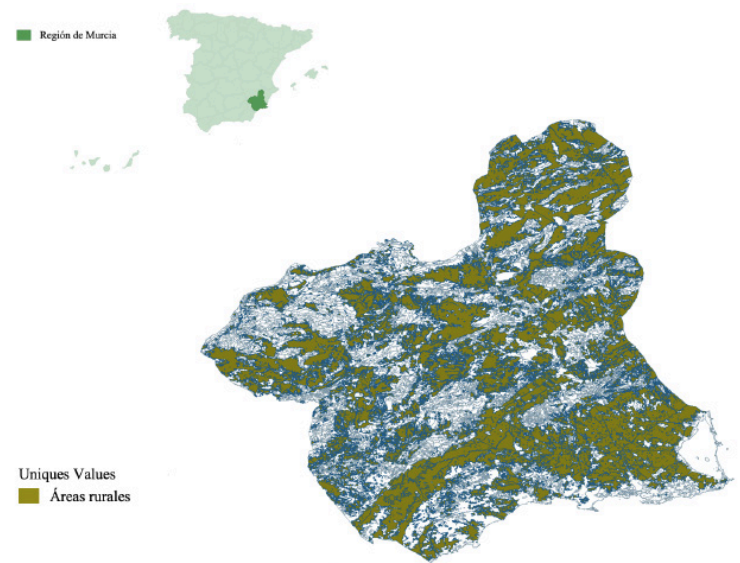

Fuente: Elaboración propia a partir de datos del Ministerio para la Transición Ecológica y el Reto Demográfico (2019).

\section{Figura 4}

\section{Distribución de la población de la Región de Murcia}

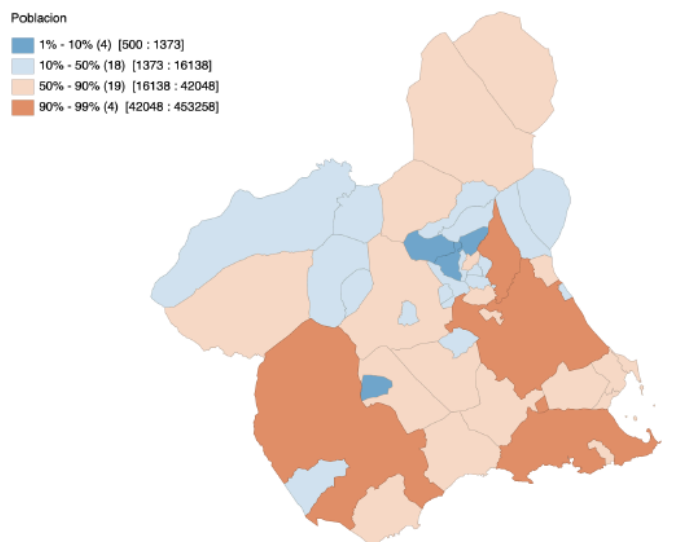

Fuente: Elaboración propia a partir de datos del Centro Regional de Estadística de Murcia (2019). 


\section{Cuadro 1}

\section{Datos básicos sobre la iniciativa LEADER}

\begin{tabular}{ccc}
\cline { 2 - 3 } & PERIODO & REGIONES ELEGIBLES \\
\hline LEADER I & $1991-1994$ & Objetivo 1 y zonas $5 \mathrm{~b}$ \\
\hline LEADER II & $1994-1999$ & Objetivo 1 y zonas $5 \mathrm{~b}$ \\
\hline LEADER + & $2000-2006$ & Todo el territorio \\
\hline LEADER & $2007-2013$ & Todo el territorio \\
\hline LEADER & $2014-2020$ & Todo el territorio \\
\hline
\end{tabular}

Fuente: Elaboración propia.

Cuadro 2

Medidas LEADER y \% de inversión total prevista

\begin{tabular}{llc}
\hline Núm. & \multicolumn{1}{c}{ MEDIDA } & \% INVERSIÓN \\
\hline 1 & Asistencia técnica al desarrollo rural & 4,4 \\
\hline 2 & Formación profesional y ayuda al empleo & 5,7 \\
\hline 3 & Turismo rural & 51,8 \\
\hline 4 & Apoyo a PYMES artesanales y servicios locales & 15,7 \\
\hline 5 & Valorización y comercialización de productos agrarios & 14,7 \\
\hline 6 & Otras medidas & 2,6 \\
\hline 7 & Funcionamiento y equipamiento del Grupo & 5,1 \\
\hline
\end{tabular}

Fuente: Elaboración propia a partir de Blanco y Benayas (1994).

\section{Cuadro 3 \\ Distribución porcentual del presupuesto}

\begin{tabular}{llc}
\hline Núm. & \multicolumn{1}{c}{ FINANCIACIÓN } & \% DE FINANCIACIÓN \\
\hline 1 & Participación comunitaria & 39 \\
\hline 2 & Otros fondos públicos & 27 \\
\hline 3 & Financiación privada & 34 \\
\hline
\end{tabular}

Fuente: Elaboración propia a partir de Luzón y Pi (2002). 


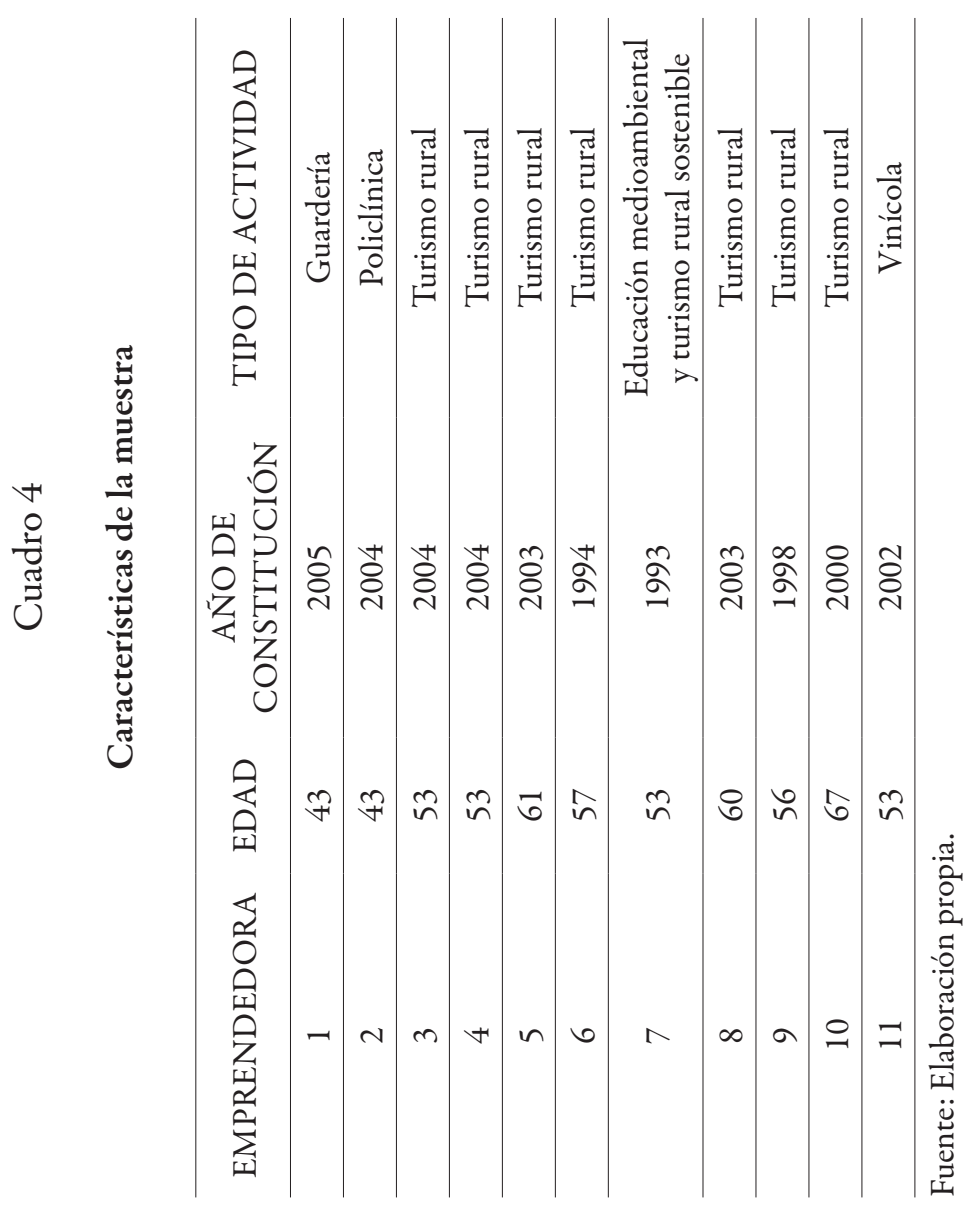




\section{Cuadro 5}

\section{Formación}

\begin{tabular}{ll}
\hline \multicolumn{1}{c}{ FORMACIÓN } & \multicolumn{1}{c}{ CENTRO } \\
\hline Diplomada en Empresariales & Universidad de Murcia \\
\hline Diplomada en Magisterio & Escuela Normal de Magisterio de Murcia \\
\hline Licenciada en Geografía e Historia & Universidad de Murcia \\
\hline Educación Primaria & Colegio de Lorca \\
\hline Licenciada en Educación Ambiental & Universidad de Murcia \\
Máster en Educación Ambiental & Instituto de Archena \\
\hline Bachiller & Universidad de Córdoba \\
\hline Licenciada en Biología & Universidad de Murcia \\
\hline Diplomada en Graduado Social & Colegio de las Palas \\
\hline Educación Primaria & Universidad de Murcia \\
\hline Diplomada en Fisioterapia & Escuela de Ópticos de Madrid \\
\hline Diplomada en Óptica & \\
\hline
\end{tabular}

Fuente: Elaboración propia. 


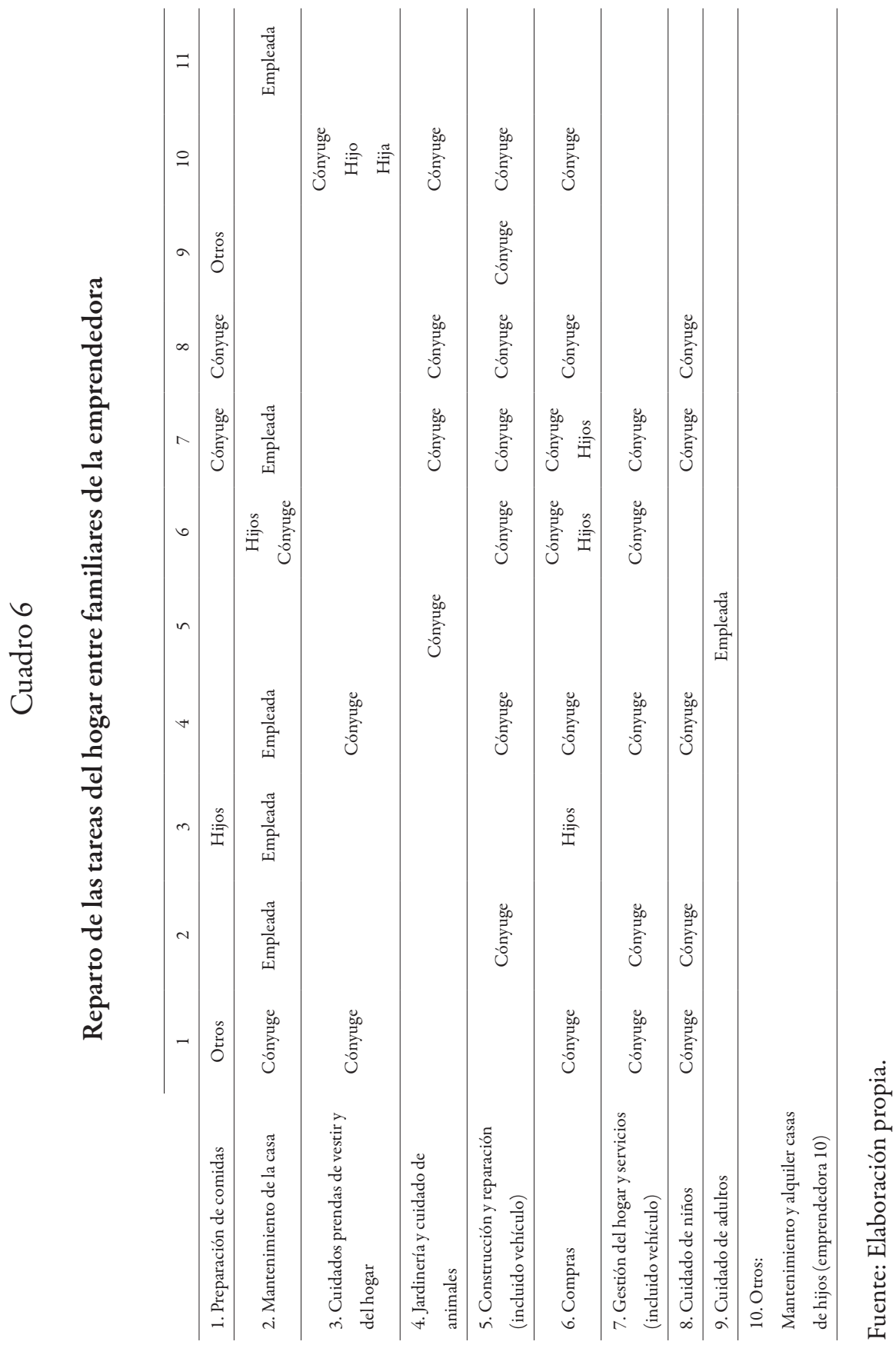




\section{Cuadro 7}

\section{Motivos para emprender}

\begin{tabular}{cl}
\hline EMPRENDEDORA & \multicolumn{1}{c}{ MOTIVO } \\
\hline 1 & $\begin{array}{l}\text { "Fue por mis hijas, por poder estar con mis hijas... cómo es po- } \\
\text { sible que aquí sólo está la guardería pública". }\end{array}$ \\
\hline 2 & "Por ampliar un negocio ya existente". \\
\hline 3 & "Por casualidad, una amiga mía tenía". \\
\hline 5 & "Para ayudar al mantenimiento de una finca agrícola". \\
\hline 6 & $\begin{array}{l}\text { "Porque al jubilarse mi marido nos quedábamos los dos sin tra- } \\
\text { bajo y comer hay que comer". }\end{array}$ \\
\hline 7 & $\begin{array}{l}\text { "En realidad fue casual, el alcalde de Moratalla, que era amigo } \\
\text { nuestro, vino y desarrolló la iniciativa Leader. No tenía a nadie } \\
\text { donde ejecutarlo y entonces nos dijo que si empezábamos no- } \\
\text { sotros". }\end{array}$ \\
\hline 8 & "Por motivación personal". \\
\hline 9 & $\begin{array}{l}\text { "Me gustaba el sector y siempre he pensado que un negocio } \\
\text { solo no era suficiente". }\end{array}$ \\
\hline 10 & "Nos gustaba mucho el campo". \\
\hline 11 & $\begin{array}{l}\text { "La casa era muy grande, la hemos disfrutado durante muchísi- } \\
\text { Los años, mis hijos, mis padres, mis sobrinos, mis hermanos... } \\
\text { querían venir.... }\end{array}$ \\
\hline "Yo trabajaba en un restaurante, llevaba prácticamente yo sola \\
toda la cocina y me pagaban muy poco".
\end{tabular}

Fuente: Elaboración propia. 


\section{Cuadro 8}

\section{Ventajas e inconvenientes de emprender}

\begin{tabular}{|c|c|}
\hline VENTAJAS & INCONVENIENTES \\
\hline $\begin{array}{l}\text { "La tranquilidad que tienes no estando } \\
\text { todo el día pensando me tocará que me } \\
\text { echen o no me tocará". }\end{array}$ & “Tener trabajadores". \\
\hline $\begin{array}{l}\text { "La flexibilidad de horario, porque al te- } \\
\text { ner niños poder decidir tú el horario, no } \\
\text { depender, te hace mucho". }\end{array}$ & "La responsabilidad". \\
\hline “Disponer del tiempo como tú quieras”. & "No lo tengo cerca". \\
\hline $\begin{array}{l}\text { "Tienes tu propio horario y trabajas } \\
\text { cuando quieres". }\end{array}$ & "La responsabilidad es tuya". \\
\hline $\begin{array}{l}\text { "Satisfacción personal de llevar tu empresa, } \\
\text { de poder obtener un beneficio económico". }\end{array}$ & $\begin{array}{l}\text { "La esclavitud de no tener horario, de } \\
\text { trabajar como una mula, no tener días de } \\
\text { fiesta, porque los días de fiesta es cuando } \\
\text { más se trabaja, no tener libertad". }\end{array}$ \\
\hline $\begin{array}{l}\text { "El rendimiento económico para ti es } \\
\text { mayor". }\end{array}$ & “Trabajas más horas, claro”. \\
\hline $\begin{array}{l}\text { "La autonomía, la satisfacción profesional } \\
\text { y desarrollo de la creatividad empresarial". }\end{array}$ & $\begin{array}{l}\text { "La carga de responsabilidad, la dureza } \\
\text { de los horarios.... }\end{array}$ \\
\hline "Que sea yo la que gobierne mi tiempo". & $\begin{array}{l}\text { "No se separa la vida familiar del } \\
\text { negocio". }\end{array}$ \\
\hline $\begin{array}{l}\text { "Puedes disponer de tu tiempo como } \\
\text { quieres". } \\
\text { "La autorrealización para mí es importante". }\end{array}$ & "No tienes horas". \\
\hline $\begin{array}{l}\text { "Nosotros tenemos aquí nuestra casa, } \\
\text { nosotros venimos aquí todos los fines de } \\
\text { semana, haya clientes o no haya". }\end{array}$ & $\begin{array}{l}\text { "No considero que trabajo muchas } \\
\text { horas porque yo las disfruto..." }\end{array}$ \\
\hline $\begin{array}{l}\text { "La independencia de los horarios". } \\
\text { "La satisfacción de que te digan pues sabes } \\
\text { que tu vino les encanta, lo estoy vendiendo } \\
\text { de maravilla". }\end{array}$ & $\begin{array}{l}\text { "El transporte, que la tengo lejos de casa". } \\
\text { "Si colaboraran más en mi casa, podría } \\
\text { dedicarle más tiempo". } \\
\text { "Son muchas horas cuando estamos en } \\
\text { la temporada". }\end{array}$ \\
\hline
\end{tabular}

Fuente: Elaboración propia. 


\section{Cuadro 9 \\ Problemas o dificultades en la creación de su empresa}

"El sector turístico funciona bien o mal en la medida de la publicidad que haga la Comunidad Autónoma de esta región”.

"Por el tema de la vid no dan subvenciones, todo lo contrario, desde 1986 está prohibido plantarlas, fomentan el que se arranquen. De esa plantación que yo tenía, pues todos los años hacen fotografías aéreas y se ve la plantación que yo tengo, entonces se ve la plantación que yo he hecho nueva, pues esa he tenido que coger los derechos de otra plantación que tenía mi padre para regularizar la parte nueva. Si no llego a tener esa, pues a mí vienen y me dicen: oye, quién te ha dicho que plantes tú esto en el 2000 o en el 89. Luego a luego, te cogen el tractor y automáticamente ellos, mandan el tractor a arrancarlo todo”.

"Porque no podemos pagar en función de que es una bodega, una bodega pequeña, la lleva una mujer. Porque no reunimos unos requisitos para que pueda ser que una persona, una familia pudiera optar a eso, pueda vivir de eso, sin tener que estar pagando pues dos mil euros por cada tres meses, o tres mil euros...."

"Problemas a la hora de iniciar la empresa el hecho de ser mujer y tener más de cincuenta años. Entonces no los tenía todavía, pero cuando te ven mujer y mayor de cuarenta... entonces hay dos calificativos o eres tonta o... Aquí al lado, en el ayuntamiento tuve muchos problemas, no me tomaban en serio".

"La discriminación de la mujer en el mundo empresarial se manifiesta de manera bastante evidente. Porque cuando nos dieron las subvenciones, a mí por ejemplo, como mujer empresaria, no se me olvidará jamás en la vida, me dieron doscientas mil pesetas. Entonces, eso más que un reconocimiento o una ayuda, para mí fue una humillación. O sea, darnos a una mujer empresaria 200.000 pesetas es como decirle: toma, quédate con estos cuatro duros... y te tapamos la boca. Porque a un empresario que monte una empresa y le den 200.000 pesetas es absolutamente ridículo. Entonces sí, hoy en día pues todavía seguimos sufriendo la discriminación de la mujer en el mundo empresarial. Siempre la ha habido la discriminación de la mujer en todos los ámbitos, pero en el mundo empresarial se manifiesta con mucha rotundidad y bueno, a veces tengo que morderme mucho la lengua en proyectos... en donde hay muchos hombres y, de alguna manera, intentamos meternos las mujeres y somos en alguna manera tratadas con cierta diferencia”.

Fuente: Elaboración propia. 
Catalina Nicolás Martínez. Doctora por la Universidad de Murcia, Máster en Dirección de Empresas (MBA) y Máster en Gestión de Recursos Humanos. Es profesora Contratada Doctor (DEI) en el Departamento de Economía Aplicada de la Universidad de Murcia. Principales líneas de investigación: economía social, emprendimiento, segregación ocupacional, mercado laboral, desarrollo rural y desarrollo local. Publicaciones recientes: 1) Nicolás Martínez, Catalina y Rubio Bañón, Alicia (2020), "Emprendimiento en épocas de crisis: Un análisis exploratorio de los efectos de la COVID-19", en Small Business International Review, vol. 4, núm. 2, España: Asociación Española de Contabilidad y Administración de Empresas (AECA); 2) Marín, Longinos, Nicolás, Catalina y Rubio, Alicia (2019), "How Gender, Age and Education Influence the Entrepreneur's Social Orientation: The Moderating Effect of Economic Development", en Sustainability, núm. 11, Suiza: MDPI; 3) Nicolás, Catalina, Rubio, Alicia y Fernández, Ana (2019), "Social Entrepreneur: Same or Different from the Rest?", en Voluntas: International Journal of Voluntary and Nonprofit Organizations, núm. 30, Estados Unidos: Springer New York.

César García Pina. Doctorando en la Universidad de Murcia y Máster en Desarrollo Local y Empleo. Es profesor externo de la Universidad de Murcia. Principales líneas de investigación: desarrollo local, desarrollo rural y mercado laboral. Publicaciones recientes: 1) García Pina, César, Solano Báez, María del Carmen y Riquelme Perea, Prudencia (2020), "Las mujeres como agentes para la cohesión territorial de los destinos turísticos rurales", en TERRA Revista de Desarrollo Local, núm. 6, España: Universidad de Valencia; 2) García Pina, César, Manzanares, Ángel y Nicolás, Catalina (2020), "La concentración del empleo en el sector turístico de la Región de Murcia (España)", en Brazilian Journal of Business, vol. 2, núm. 3, Brasil: Associação Nacional de Pesquisa e Pós-Graduação em Administração (ANPAD); 3) García Pina, César (2018), "Análisis de experiencias de recuperación y revitalización del casco histórico de Lorca”, en Journal of TourismandHeritageResearch,vol.4,núm. 1,España:iManagement\&Tourism.

Ángel Manzanares Gutiérrez. Doctor por la Universidad de Murcia y Máster en Desarrollo Local y Empleo. Es profesor Contratado Interino en el Departamento de Economía Aplicada de la Universidad de Extremadura y profesor colaborador de la Universitat Oberta de Catalunya. Principales líneas de investigación: desarrollo local, desarrollo rural y mercado laboral. Publicaciones recientes: 1) Manzanares, Ángel y Riquelme, Prudencio 
(2017), "Análisis espacial del desempleo en los mercados locales de trabajo españoles", en Revista Galega de Economía, vol. 26, núm. 2, España: Universidad de Santiago de Compostela; 2) Manzanares, Ángel y Riquelme, Prudencio (2017), "La concentración industrial de las empresas en los mercados locales de trabajo de la Región de Murcia”, en Tribuna de Economía Revistas ICE, núm. 895, España: Instituto para la Competitividad Empresarial; 3) Manzanares, Ángel, Sánchez, Celia y Riquelme, Prudencio (2016), "Análisis de la coherencia en los mercados locales de trabajo de la provincia de Huelva", en Revista de Estudios Regionales, núm. 107, España: Universidades Públicas de Andalucía.

Prudencio José Riquelme Perea. Doctor por la Universidad de Murcia, profesor Titular del departamento de Economía Aplicada y Decano de la Facultad de Ciencias del Trabajo de la Universidad de Murcia. Principales líneas de investigación: desarrollo local, desarrollo rural, mercado laboral, economía social y calidad de vida. Publicaciones recientes: 1) Riquelme, Prudencio, López-Martínez, María, De Maya, Manuel (2020), "Measurement of Quality of Life in Spanish Regions", en Applied Research in Quality of Life, Holanda: Springer Netherlands; 2) Riquelme, Prudencio, Fernández, Ana María y López-Martínez, María (2020), "El enfoque de los mercados de trabajo segmentados: origen y evolución", en Cuadernos de Relaciones Laborales, vol. 38, núm. 1, España: Universidad Complutense; 3) Riquelme, Prudencio, López-Martínez, María, Nicolás, Catalina y Vives, Nerea (2019), "Análisis de la segregación ocupacional por género en España y la Unión Europea (2002-2017)", en Prisma Social: Revista de Ciencias Sociales, núm. 26, España: Fundación iS + D para la Investigación Social Avanzada. 